\title{
EL PACÍFICO: UN PAISAJE MONUMENTAL PRECERÁMICO DEL FORMATIVO EN LA INTERCUENCA DE LOS RÍOS CHILLÓNY RÍMAC
}

\author{
LUIS A. FLORES BLANCO \\ Universidad NaCIONAL MAYOR DE SAN MARCoS \\ Iflores78@gmail.com
}

\section{RESUMEN}

Este artículo es un primer reporte que explora los problemas de estudiar las primeras expresiones de arquitectura pública, en la costa central. Pero al mismo tiempo, se explora las potencialidades que tiene investigar un tipo de sitio precerámico de las características de El Pacífico, ubicado sobre un cerro en la intercuenca de los valles del Chillón y el Rímac. Como demostramos aquí, desde el asentamiento se tiene una gran cuenca visual, que además se sirve de la topografía para constituirse como un "lugar central" potente y significativo, dispuesto de tal manera para ser visto y constituirse como paisaje monumental.

Palabras claves: Formativo, precerámico, monumental, paisaje, cuenca visual, SIG.

\section{Abstract}

This paper is the first report that explores the problems of researching the first expressions of public architecture Archaic, on the central coast. And therefore, the potential it has to investigate a type of site as El Pacifico, located on a hill in the interbasin of the valleys of the Chillon and Rimac. And as I will demonstrated here, from the site you have a great viewshed, which also uses the topography to be as a powerful and meaningful place, arranged such to be seen and becoming a monumental landscape.

KeYwords: Formative, preceramic, monumental, landscape, viewshed, GIS. 


\section{INTRODUCCIÓN}

La idea de una ocupación remota en los Andes Centrales, y particularmente en Lima, fue sugerida desde el inicio de la arqueología peruana. Max Uhle (1910) propuso que las primeras poblaciones fueron de "pescadores extremadamente simples", en localidades como Supe, Chancay, Ancón, Bellavista y Lima, que vivían en conchales y eran portadores de una tecnología primitiva. Si bien en los años siguientes, gracias a los datos recuperados en los valles de la costa central, especialmente los de Lima, se corroboró la gran profundidad temporal de las ocupaciones costeras; al mismo tiempo se empezó a notar que ellas habían alcanzado altos grados de complejidad no antes vistas en los Andes Centrales, incluso con bases económicas donde el recurso marino era lo prioritario en la dieta. Teníamos así un desarrollo prístino que iba contra los enfoques tradicionales en la que el origen de la agricultura había jugado un rol trascendental (Engel 1957, 1958, 1987; Lanning 1967; Patterson y Lanning 1964; Moseley 1975).

En los valles y áreas intercuencas de la provincia de Lima se han realizado antiguos y extensos estudios arqueológicos de las sociedades que vivieron durante el periodo que los arqueólogos solemos llamar Arcaico Tardío o Formativo Inicial (3000-1800 a.C.) $)^{1}$, que coincide justamente con una etapa en las que las poblaciones prescindían de la fabricación y uso de la cerámica (sea ello un fenómeno precerámico o incluso acerámico). Aunque hoy se sabe que la ausencia/aparición de este elemento tecnológico no significó un cambio sustancial en la vida social prehistórica.

Han pasado muchos años desde los primeros trabajos sobre el Formativo Inicial en la costa central. Pero no cabe duda que luego de las investigaciones iniciadas por Ruth Shady (1997) y su equipo en el valle de Supe, hace más de veinte años, se ha incentivado el inicio de nuevas investigaciones en los valles de la costa central y norcentral. Desde entonces se han dado contribuciones importantes, tanto a escala regional (Aguilar 2006; Creamer et al. 2013; Perales 2006; Shady et al. 2000; Vega-Centeno et al. 1998) como excavaciones -muchas veces extensas- al interior de los sitios (Benfer 2007; Chu 2006, 2008; Dillehay et al. 2012; Fuchs et al. 2009; Shady 1997, 2003, 2004, 2005, 2006a, Shady 2006b; Shady y Cáceda 2006; Shady y Leyva 2003; Shady et al. 2014; Shady et al. 2016; Tosso et al. 2016; Vega-Centeno 2005, 2010). Los valles de Lima tampoco han estado exentos de nuevos estudios (Abanto 2009, 2013; Benfer 2007; Cornejo 2012, 2013; Guillen 2013). Como resultado de ello se ha logrado tener una lista amplia de sitios fechados, caracterizar e identificar patrones de arquitectura pública, conocer cómo fue la subsistencia económica e incluso se ha intentado entender las relaciones intercomunales y proponer tradiciones regionales (Cornejo 2013; Haas et al. 2004; Haas y Creamer 2006; Shady 2006a, 2006b; Shady et al. 2001; Shady y Leyva 2003; Vega-Centeno 2005, 2010). En general, estos conjuntos de datos -principalmente la arquitectura monumental- han servido a los arqueólogos para proponer que el surgimiento de la centralización del poder en los Andes Centrales se dio en este periodo temprano. Para ello se han usado tipos evolutivos de organización sociopolítica tales como jefatura compleja y/o estado prístino (Moseley 1975; Feldman 1980; Shady y Leyva 2003, Shady 2005, 2006a, 2006b; Shady et al. 2001; Haas 1987; Haas y Creamer 2006).

1. Son varios los investigadores que han llamado la atención de lo insostenible e inconsistente de seguir llamando "Arcaico" a un desarrollo tan avanzado y complejo como Caral o El Paraíso (Bueno 1997: 77; Lumbreras 2006; Onuki 1999:332; Shady 2004: 23, 252; Shibata 2004). Yo mismo he expuesto este problema (Flores 2006: 13-18). Incluso me he visto entrampado en esa problemática al decidirme qué esquema cronológico usar en este artículo. Considero que al periodo Arcaico Tardío y Final o el Precerámico V-VI (Kaulicke y Dillehay 1999; Lanning 1967) debieran ser renombrado como Formativo Inicial. Aunque ello merece una explicación y discusión amplia que escapa de los objetivos del artículo. 
No obstante, aún existen una serie de vacíos en el conocimiento que son el resultado de la forma como nos hemos aproximado al estudio del periodo Formativo en general (incluido lo que llamamos el Arcaico Tardío). Por ejemplo, no se ha logrado entender satisfactoriamente todo el sistema de asentamientos debido a que en varios casos no se han hecho estudios regionales de cobertura total (full-coverage regional survey). Más bien se ha privilegiado ubicar y excavar solo en los grandes sitios. Así, prácticamente desconocemos sobre la existencia de otros tipos de asentamientos más allá de los grandes centros públicos. No sabemos si existieron campamentos, aldeas, poblados, santuarios aislados, o paisajes culturales asociados como áreas agrícolas, caminos, tecnología hidráulica, montañas significativas, entre otros. Tampoco sabemos bien cómo fue la biografía de cada valle y la historia ocupacional de cada sitio.

Por lo cual, investigar en otro tipo de sitio resulta necesario para tener una muestra más representativa del sistema de asentamientos del periodo, especialmente para la costa central. Este déficit en el conocimiento nos motivó plantear una investigación en el sitio El Pacifico. Así, este proyecto se ha planteado primero solucionar el problema cronológico del sitio. Partimos con la idea que se trata de un asentamiento del periodo Formativo (en su sentido amplio expuesto arriba), ello debido a los trabajos previos, nuestra propia inspección de la superficie del yacimiento y las amplias referencias de otros yacimientos similares. Pero además, intentaremos indagar el rol social y político que habría cumplido El Pacifico en el sistema de asentamiento de la región y tratar de entender el proceso de monumentalización del paisaje. Este asentamiento se ubica sobre el cerro El Pacifico, en la cadena de estribaciones costeras de Lima Norte, por los 100 a 150 metros sobre el nivel del mar. Todo este territorio está en la intercuenca ubicada entre las cuencas hidrográficas de los ríos Chillón al norte y el rio Rímac al sur. En el actual distrito limeño de Los Olivos (Fig.1). Este escrito es solo un primer reporte que tiene como finalidad dar a conocer los alcances del proyecto, plantear los problemas en la que se inserta nuestro estudio y definir la potencial idad de investigar en El Pacifico.

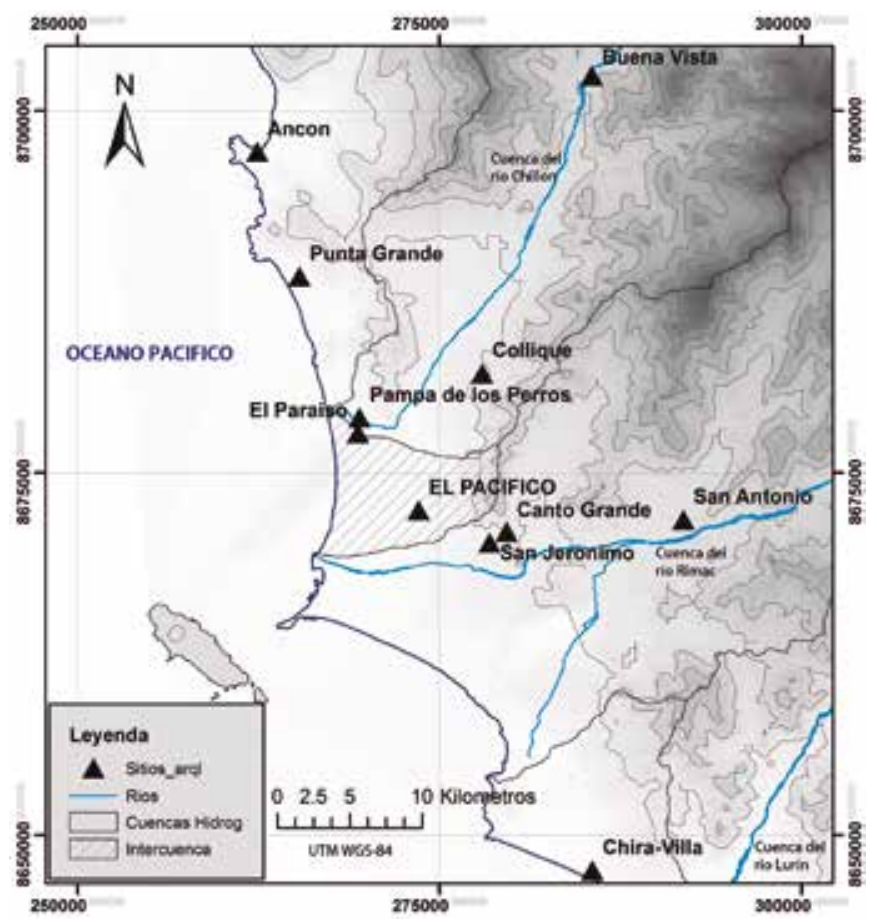

Fig.1. Mapa de distribución de los asentamientos de los periodos Formativo Final t Temprano de los valles de Lima. El Pacifico se ubica en la intercuenca de los valles de Chillón y el Rímac. 


\section{InVestigaciones Arqueologicas en los Valles de Lima}

La mayor parte de las investigaciones de los valles de Lima se han centrado en el Chillón, especialmente en su sección baja. Así tenemos referencias sobre sitios del Formativo Inicial y Temprano como El Tanque en Ancón, Punta Grande en Ventanilla, Pampa de los Perros y El Paraíso (o Chuquitanta) y tal vez Collique en el valle bajo y Buenavista al interior del valle. Ademas de una serie de conjuntos de edificios dispuestos en U como Chuquitanta, Pro, Pampa de Cueva, Huacoy y Chocas de los cuales -salvo Huacoy- solo tenemos descripciones superficiales (Benfer 2007; Cornejo 2012; Engel 1987; Guillen 2013; Lanning 1967; Quilter 1985; Quilter et al. 1991; Silva 1996 Silva y Jaime 2000). De ellos, El Paraíso ha sido, y es, un sitio icónico. Este asentamiento es el que más trabajo e interés ha recibido. Desde los trabajos pioneros de Engel (1966a; 1966b; 1967; 1987) quien reveló la arquitectura de un montículo piramidal denominado Unidad 1, hasta el posterior proyecto de Jeffrey Quilter quien esclareció la cronología del sitio, planteando una ocupación corta para el sitio (máximo de 400 años), reveló mayores componentes arquitectónicos y demostró que la economía de subsistencia era una mezcla de recursos marinos, principalmente basados en peces como la anchoveta, y vegetales, entre tubérculos, legumbres y frutales (Quilter 1985; Quilter et al. 1991). Todos estos datos han servido para plantear que El Paraíso habría sido uno los primeros centros ceremoniales y presión material del poder primigenio en los Andes (Engel 1966a; 1966b; 1967; 1987; Lanning 1967: 69; Quilter et al. 1991).

Otros sitios en el valle bajo del Chillón son Pampa de los Perros y el que se habría ubicado en el actual hospital de Collique. Pampa de los Perros se encuentra prácticamente al frente, en la otra margen del rio, de El Paraíso. El sitio consiste en una estructura piramidal orientado de este a oeste, que cuenta con una plaza circular al frente, y montículos menores hacia su lado sur (Cornejo 2012). Del asentamiento en Collique solo se conoce que habría sido un montículo piramidal de dos plataformas y una plaza circular (Silva 1996: 130).

De los edificios en U del valle del Chillón destaca Huacoy de casi 30 hectáreas, con un gran edificio central (en la base de la U) de 25 metros de altura y 250 metros de largo y con largos brazos laterales de mas de 500 metros (Silva y Jaime 2000). El edificio esta construido en base a piedras cortadas, cantos rodados, adobes hemisfericos y shicras y al parecer sus paredes2 estuvieron cubiertos con frisos no bien conocidos aun (Ludeña 1973).

En el valle medio del Chillón se ubica Buena Vista, un asentamiento preceramico donde se ha excavado dos estructuras monumentales, construidas mediante plataformas aterrazadas a una colina. El Montículo I es un edificio de unos $11 \mathrm{~m}$ de altura, sobre la cima de esta pirámide destaca el hallazgo del Templo del Zorro, con una ocupación final por los 2200 a.C.; aunque se avizora la existencia de una larga superposición de ocupaciones por debajo. Mientras el Montículo II es otra estructura con plataformas aterrazadas y que presenta una cima con una serie de recintos ordenados jerárquicamente que nos hace recordar a la Unidad I de El Paraíso. Aquí fue encontrada la escultura del disco solar (Benfer et al. 2007).

Sobre el piso, de la intercuenca de ambos valles, se levanto Garagay, un conjunto de tres edificios dispuestos rodeando una plaza central, configurando una U que se orienta hacia el noreste. Todo el asentamiento tiene un área de 25 hectáreas. Del sitio se ha excavado el atrio del edificio principal, donde se han develado impresionantes frisos, así como algunos de sus accesos, el brazo derecho y una plaza circular. La pirámide principal $140 \mathrm{~m}$ de lado y $23 \mathrm{~m}$ de alto, mientras los brazos son mas bajos y cuadrangulares (122x100 m) (Ravines 1991; Ravines e Isbell 1975). A escasos 800 metros del cerro El Pacifico.

Más al sur, en el valle del Rímac se dio a conocer el sitio Chira-Villa, ubicado a pocos metros del mar, con evidencias de niveles tanto del Formativo Inicial (precerámico) como del Formativo Temprano. Se trata de un yacimiento con ricos restos marinos, especialmente malacológicos, muros de guijarros, instrumentos líticos sobre cuarcita y basalto, redes y textiles entrelazados de algodón (En- 
gel 1957, 1958; Lanning 1960, 1967; Patterson y Moseley 1968). Aunque recientemente se ha puesto en duda su posición cronológica (Escarcena 2010).

También se han reportado sitios en las lomas del valle del Rímac. En el cuello de la quebrada de Amancaes, el paso natural desde la pampa del actual distrito del Rímac hacia San Juan de Lurigancho se encontraba un sitio precerámico llamado Canto Grande o 15 de Enero o estructura precerámica del cuello de Amancaes (Abanto 2009, 2013; Roselló 1997). En este sitio sobresalía una estructura monticular cuadrangular de $100 \mathrm{~m}$ de lado, levantado con una sucesión de plataformas y conteniendo dos plazas circulares a desnivel alineadas al eje del edificio. La primera plaza estaba inscrita en una plataforma delantera, y el otro encerrado en una especie de atrio, construida sobre una plataforma más elevada, que a su vez se comunicaba con la parte más encumbrada del edificio. Pero además, el yacimiento contaba con otras estructuras laterales, que al parecer delimitaba una amplia plaza central (Abanto 2009, 2013; Roselló 1997). El sitio, de más de 1.5 hectáreas, e incluso asociado a una serie de geoglifos, fue tan importante que el edificio principal habría sido "el doble del también precerámico de Chuquitanta" (Roselló 1997: 73). Lamentablemente fue arrasado en los años 70 (Abanto 2013).

Muy cerca de este yacimiento, pero ya sobre el suelo del valle se levanta el templo en U de La Florida, cuya primera ocupación, así como otras evidencias de la pampa de Amancaes (como la huaca que existió en el actual parque Juan Ríos), se ha señalado tuvo una ocupación de finales del preceramico, durante la fase San Jacinto (Fuentes 2009).

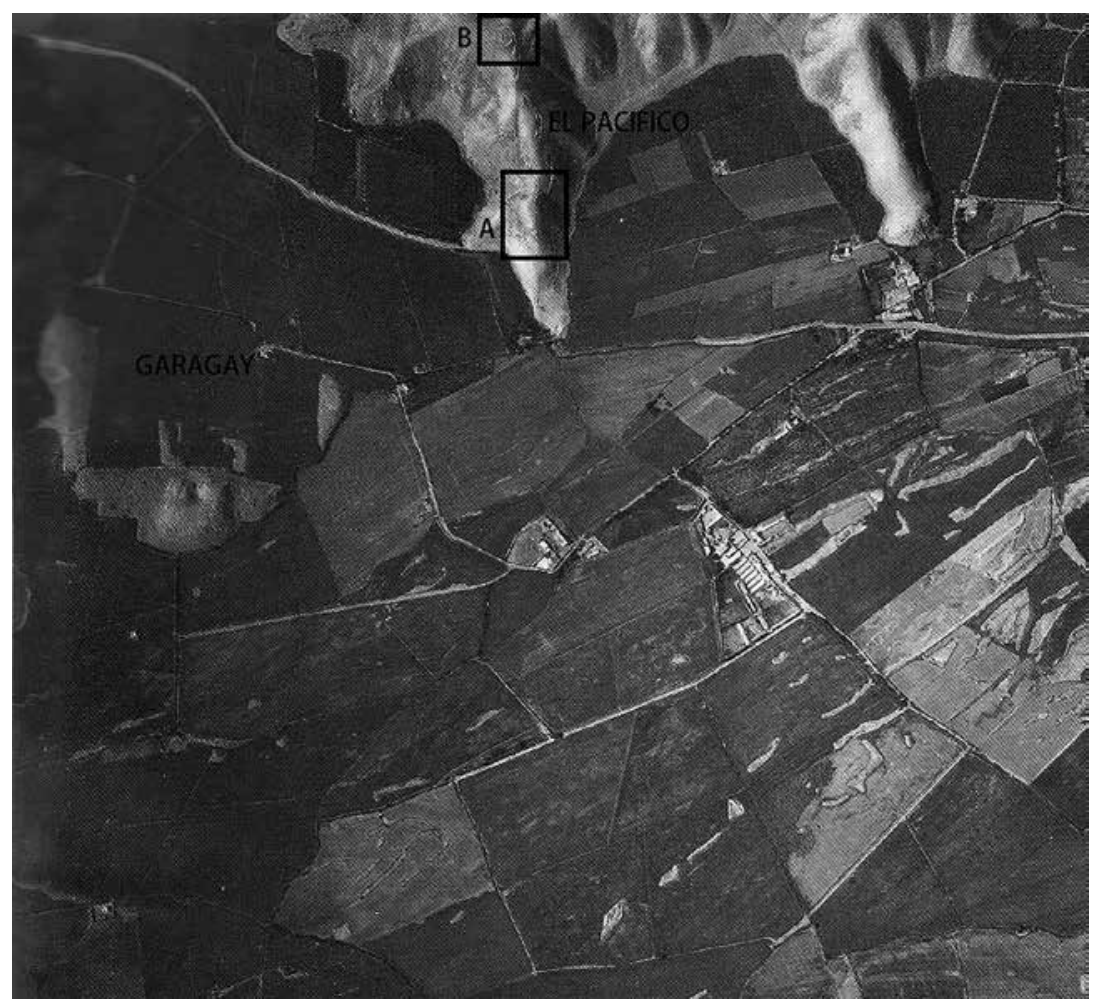

Fig.2. La sección noroeste de la Fotografía Aérea del SAN. 1112-2.4; desde donde se aprecia el asentamiento El Pacifico sobre el cerro del mismo nombre y al frente el sitio en U de Garagay (Roselló 1997: lámina XIX). 
Recientemente, en la localidad de Huachipa, al interior del valle del Rímac, el arqueólogo Jonathan Palacios ha comunicado que debajo del templo en U de San Antonio logró ubicar una estructura piramidal del Arcaico Tardío, de la cual hasta el momento se conoce solo unas escalinatas y la base del montículo (El Comercio 2011)

\section{Primeras Investigaciones en el Sitio Arqueológico el Pacifico}

El Pacifico fue dado a conocer en un artículo de Teddy Traslaviña, Natalia Haro y Edgar Bautista (2007). A los autores les llamó la atención una anomalía identificada en una de las fotos áreas de la publicación de Lorenzo Roselló (1997: lámina XIX) (Fig.2). Precisamente en dicha lámina se pueden observar los centros ceremoniales de Condevilla y Garagay, y en el cerro próximo se aprecia una serie de círculos concéntricos sobre el cerro El Pacifico.

Después de una serie de visitas que los autores hicieran de la zona, ellos pudieron identificar, en el 2005, primero "un montículo de unos 3 a $4 \mathrm{~m}$. de alto y una base de aproximadamente 30 x 30 m.", además de un corte estratigráfico expuesto de otra estructura (Traslaviña et al. 2007).

El sitio fue tentativamente asignado al periodo de uso de las shicras, un elemento tecnológico de fibra trenzada que se utiliza para hacer bolsas (Traslaviña et al. 2007: 32-33, 38), que como se sabe su uso se extendió hasta las sociedades pre-Chavín, durante el periodo Formativo Medio. Sumado a ello, por la ausencia de cerámica en superficie los autores sugirieron que cronológicamente El Pacifico tiene "evidencias de un probable sitio del Arcaico Tardío" (Traslaviña et al. 2007). Más allá de este importante aporte a nivel de superficie, los autores no pudieron corroborar sus hipótesis con excavaciones controladas. Temas tan básicos como la cronología y la caracterización microespacial del sitio se mantuvieron desconocidos.

Más recientemente, en el 2011 se realizó un Proyecto de Evaluación Arqueológica (PEA) en los cerros de Pacifico y Mulería (Luján 2011). Este proyecto tuvo como finalidad deslindar el área libre de evidencias arqueológicas, logrando determinar la existencia de 5 poligonales con restos arqueológicos. Esto lo hicieron mediante 26 unidades de excavación.

Para el caso específico de El Pacifico, durante la ejecución de este PEA se volvió a sectorizar el sitio, desconociendo con ello la sectorización ya antes descrita por Traslaviña y sus colegas (2007). Es así que lo que antes se nominó como Sector A (según Traslaviña et al. 2007), ahora este proyecto lo sectorizó como Sector B, mientras lo que antes era Sector B ahora era Sector A. Dándose una alteración de la nominación. Nuestro proyecto respetará esta última sectorización, porque además es la que reconoce legalmente el Ministerio de Cultura como parte de la delimitación y señalización del sitio, tal como ha sido propuesta, de manera separada en los sectores A y B (Lujan 2011). Aunque por razones científicas, entenderemos el sitio como un todo, como una unidad social espacial.

De cualquier modo, en El Pacifico se realizaron 4 cateos de $2 \times 2 \mathrm{~m}$ cada uno, todos ubicados en lo que llamaron el Sector B, dos dentro del montículo y dos en los alrededores. Las excavaciones permitieron demostrar que estratigráficamente se trata de un sitio sin presencia de cerámica. Y por otro lado, que existen evidencias arquitectónicas enterradas, como el piso elaborado que se logró mostrar en la Unidad 1. Desafortunadamente no hay mayores detalles estratigráficos porque la excavación culminó mostrando solo la última ocupación (Lujan 2011). Las conclusiones de este PEA señalan que estos dos montículos (subsectores A y B) son los más antiguos, siendo el sector A la expresión más primigenia (Arcaico Tardío), mientras el subsector B tal vez tuvo una continuación incluso hasta el Formativo (Lujan 2011). No obstante, todas estas conclusiones están basadas en apreciaciones tales como que la evidencia de shicras y muros de cantos rodados son pruebas de la antigüedad del edificio. 
Finalmente, la estudiante Lucero Cayo Quispe (2015) realizó un trabajo de registro del asentamiento, especialmente de los paramentos expuestos en el perfil este del Sector A, para su curso de Pregrado II de la Universidad Nacional Mayor de San Marcos.

En resumen, El Pacifico ha sido subdividido en dos sectores, dispuestos en altitudes distintas, cada una ubicada en las dos únicas explanadas que presenta el cerro. En ambos casos se tratan de estructu-

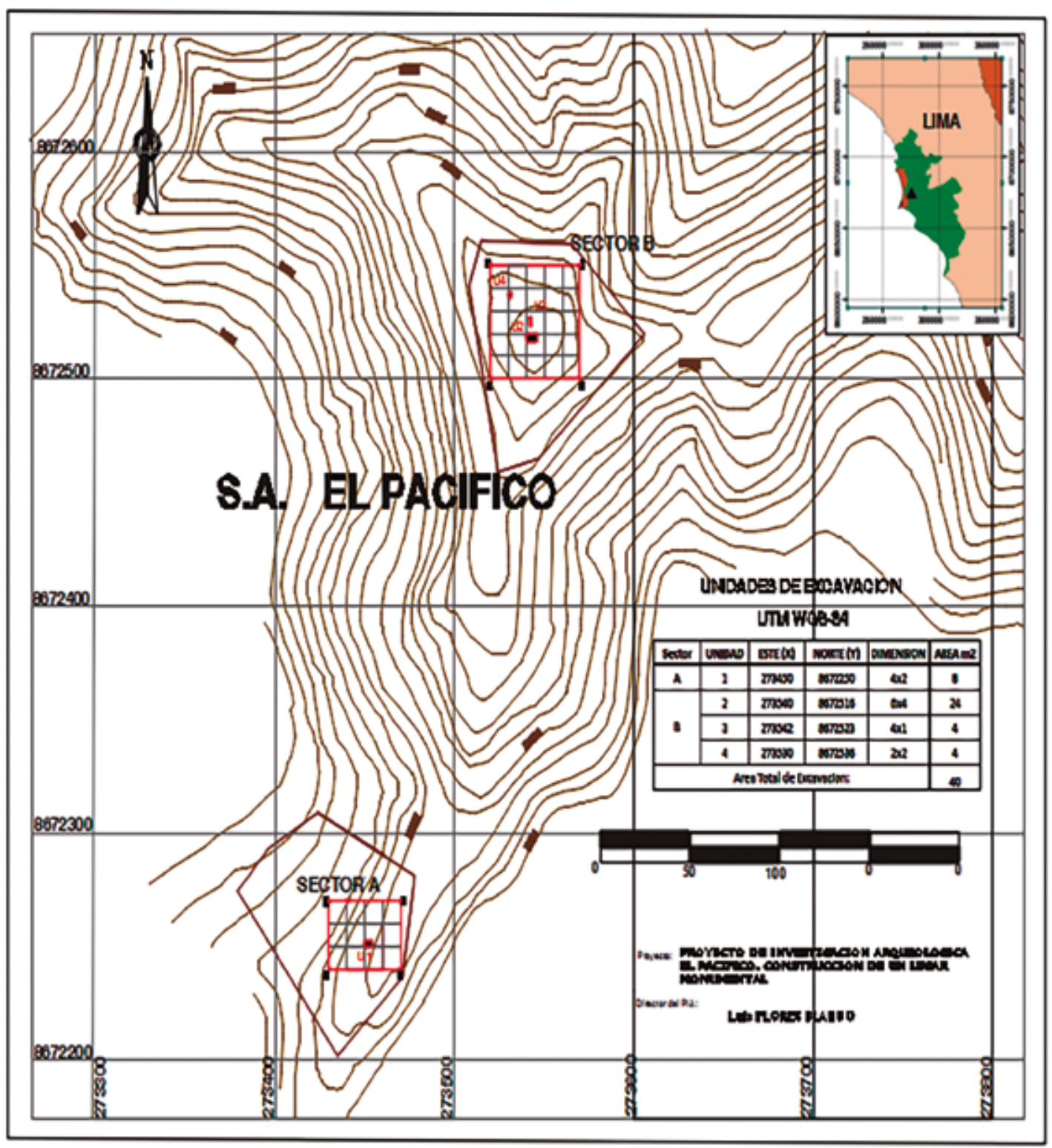

Fig.3. Los sectores A y B del sitio El Pacifico, con la ubicación de las unidades que serán intervenidos durante nuestro proyecto. 


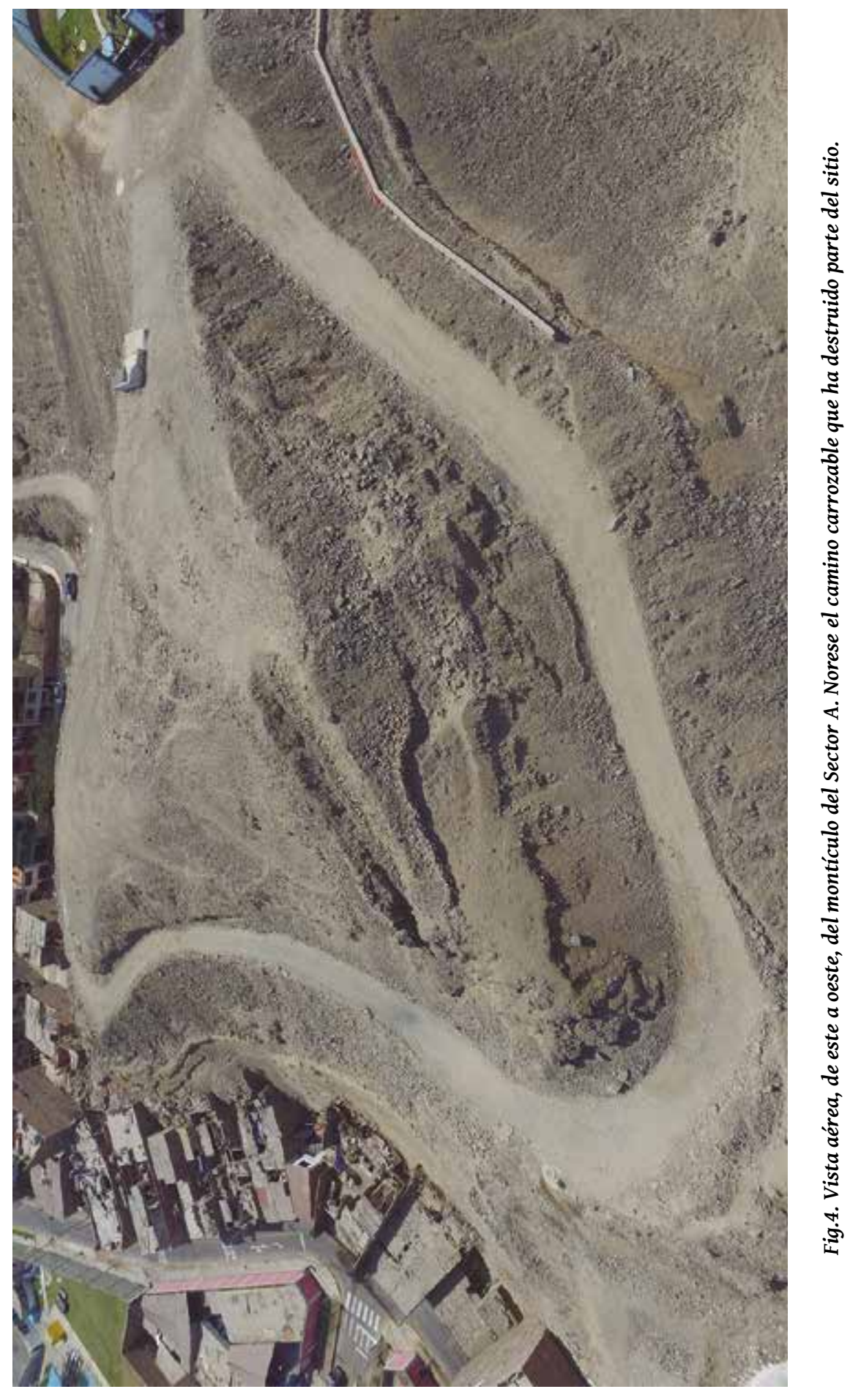




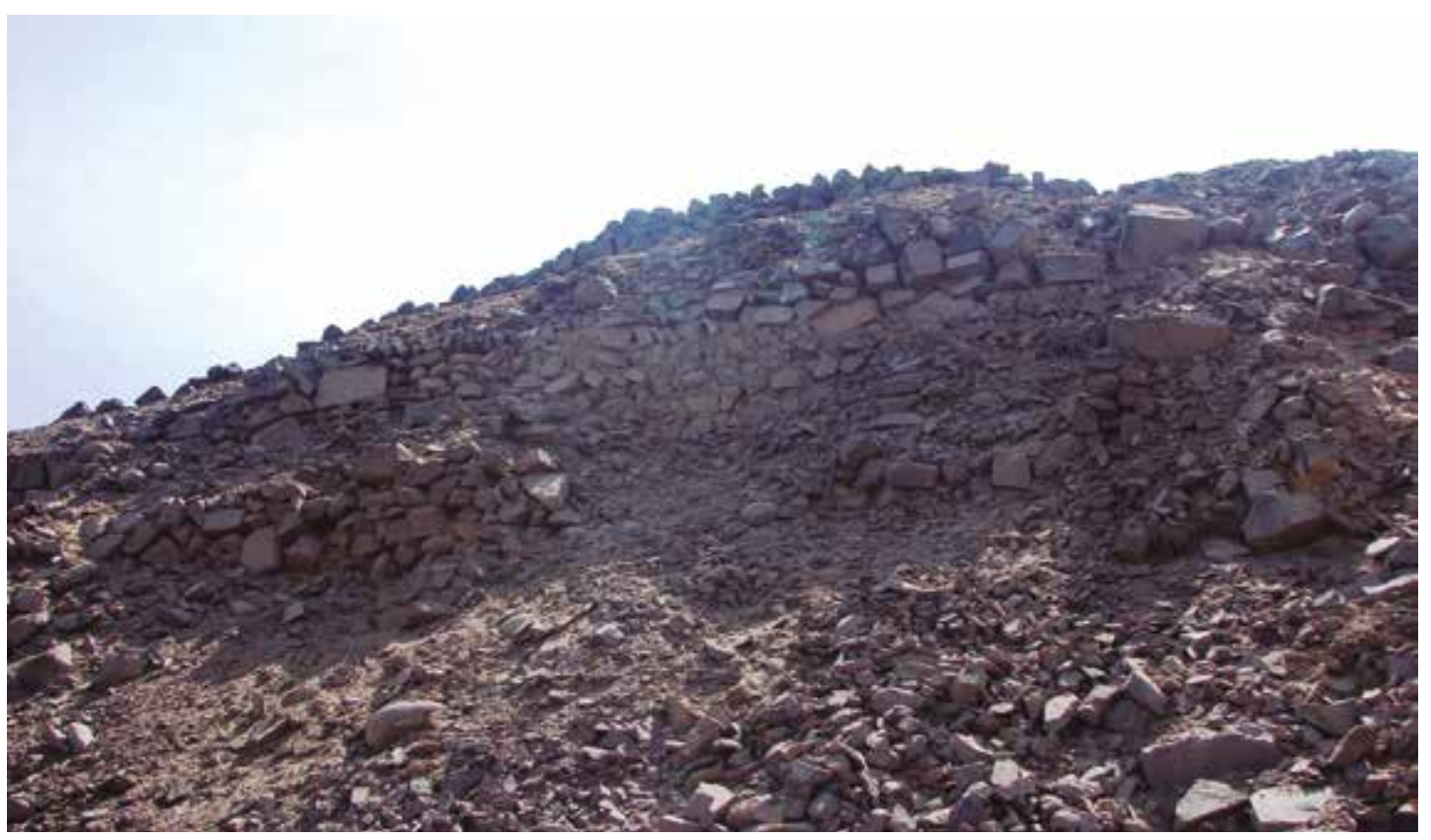

Fig. 5. Vista este-oeste del paramento de piedras expuesto en el perfil este del montículo del sector A. En dicho perfil también se pueden apreciar bolsas de fibras (shicras).

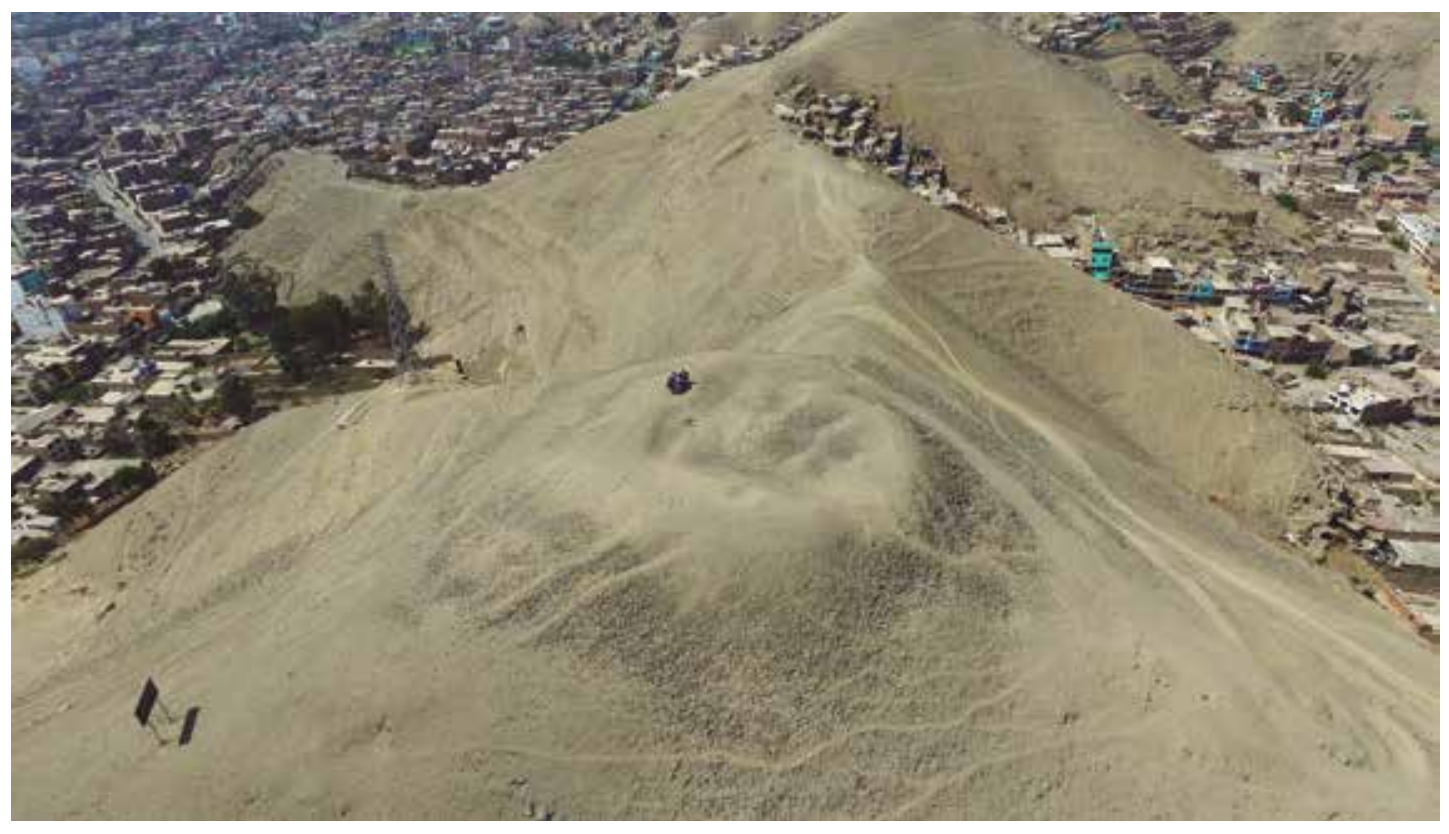

Fig. 6. Vista aérea, desde el oeste, del montículo del Sector B. 


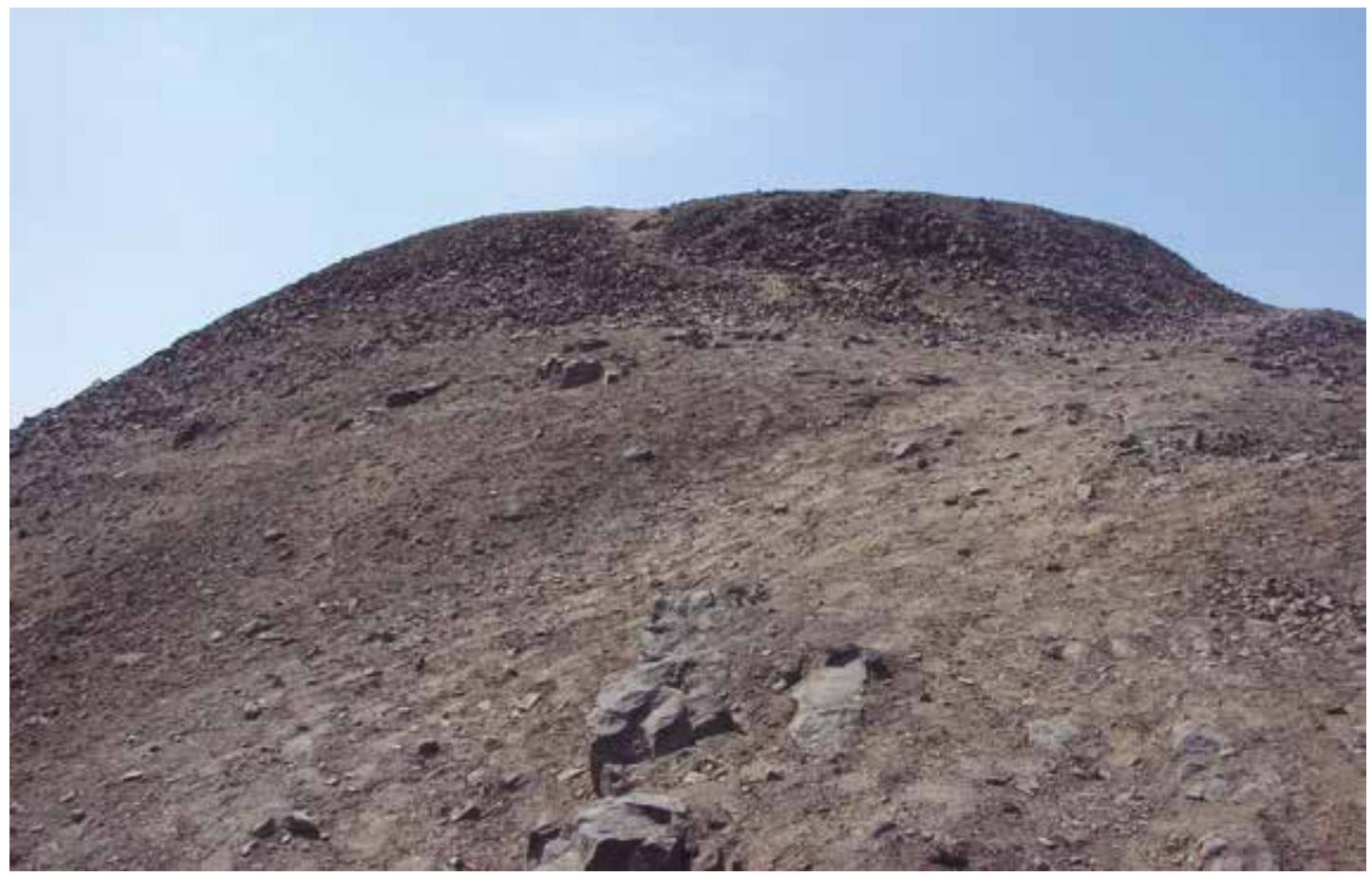

Fig. 7. Vista sur-norte del montículo del sector B del sitio.

ras monticulares menores. El sector A es el que se encuentra ubicado en una posición topográfica más baja. Mientras el Sector B en el lugar más alto (Fig. 3).

- El Sector A o Montículo de la parte baja. Se ubica colindante al camino que va hacia el pozo de Sedapal, sobre los $100 \mathrm{msnm}$. Este sector ha sido definido por una serie de evidencias expuestas, como un perfil de aproximadamente $60 \mathrm{~m}$ donde se expone muros de piedras de cantos rodados y piedras cortadas que serían parte de edificios superpuestos (Fig.4 y 5). En algunas secciones expuestas aún puede apreciarse un enlucido amarillo, rellenos de piedras, shicras y piezas textiles de algodón (Traslaviña et al. 2007: 38-41). En el lado norte del perfil se aprecia además, una sucesión de muros de plataformas o terrazas que se superponen. Estas evidencias son la prueba del clásico enterramiento de estructuras, ampliamente dado a conocer para el Formativo Inicial (Bonnier 1997; Onuki 1999). Mientras la cima del edificio tiene una planta inclinada hacia el norte y un corte abierto en su lado sur, donde incluso puede observarse la roca madre. Finalmente, en la parte noroeste del sector se puede identificar una terraza acondicionada a la parte más baja del cerro, donde se concentra gran cantidad de cantos rodados sobre la superficie y se puede distinguir algunas alineaciones de piedras que configuraría una larga plataforma. Por estos datos, es posible inferir que la fachada del edificio estuvo hacia el noroeste.

- El Sector B o Montículo de la parte alta. Se ubica en la cima del cerro, por los $150 \mathrm{msnm}$. Se trata de un montículo cuadrangular, de $40 \mathrm{~m}$ de lado y $10 \mathrm{~m}$ de altura. El montículo presenta una superficie cubierta con piedras angulosas cortantes (Figs. 6 y 7) y se asienta sobre un afloramiento rocoso, alrededor del cual se habría construido terrazas de piedra, seguramente dándole una apariencia aterrazada. En la cima de dicho montículo se pudo distinguir una superficie sinuosa, más elevada en el 
centro, que en total tiene $22 \mathrm{~m}$ de lado. Precisamente, en dicha cima se puede identificar alineaciones de piedras, que configuraría un gran edificio orientado al noroeste ( $\left.\mathrm{N} 40^{\circ} \mathrm{W}\right)$. Este edificio está dividido por un muro central de $50 \mathrm{~cm}$ de ancho, elaborado en piedras cortadas de unos $15 \mathrm{~cm}$., organizadas en planta en dos hileras. Dicha división configura al menos en dos grandes espacios, uno al norte más amplio que el otro localizado al sur.

\section{La Visibilidad y Disposición de el Pacifico en el Paisaje}

El trabajo previo en El Pacifico dejó la sugerente hipótesis que desde este asentamiento existió una conexión visual importante con un supuesto yacimiento temprano al costado del sitio del Formativo Medio de Pampa de Cueva (Traslaviña et al. 2007). Y se pensó que tal vez esto se debió a una búsqueda por establecer lazos de visibilidad entre los edificios de planta en $U$ del periodo

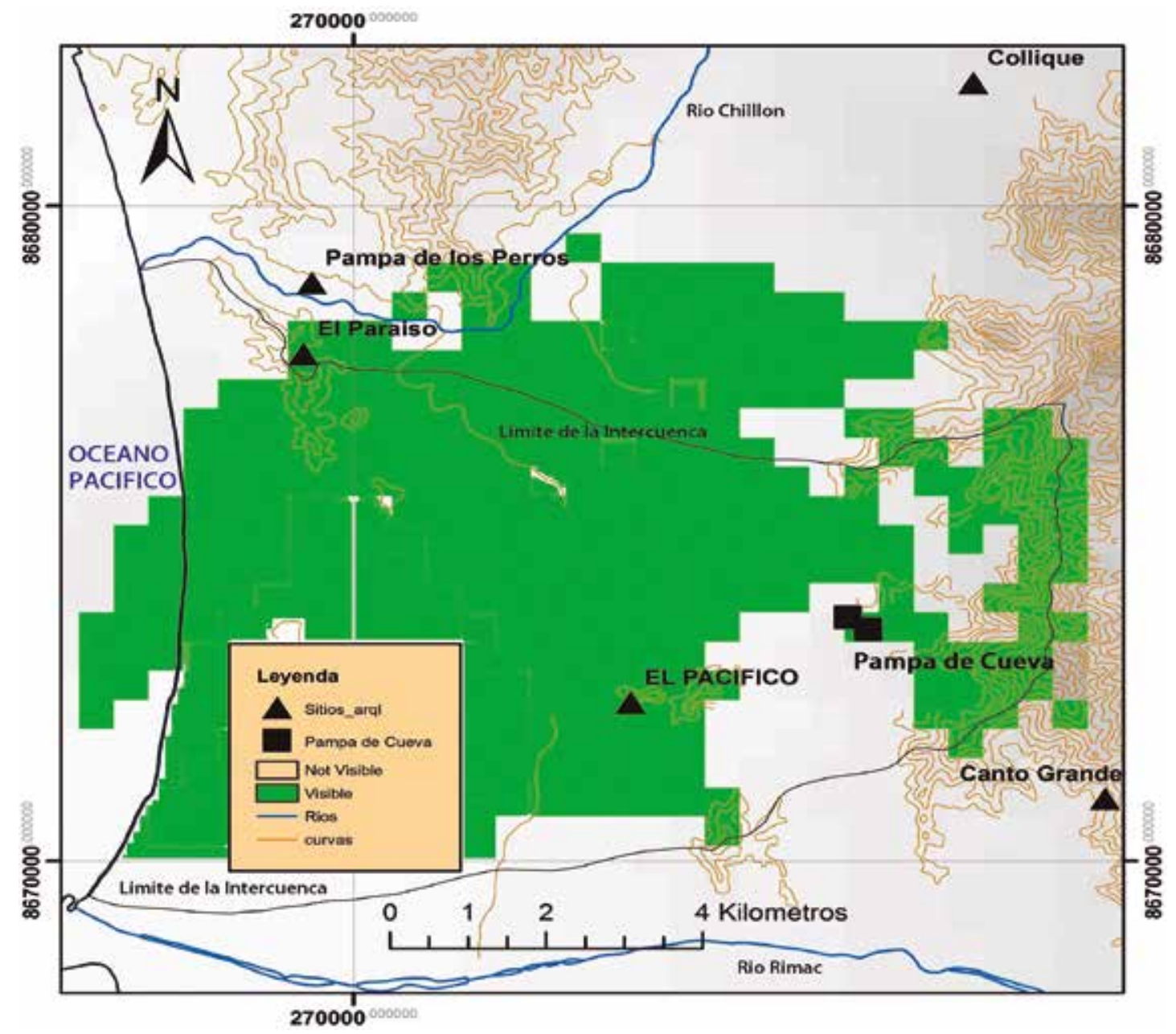

Fig. 8. Mapa de la cuenca de Intervisibilidad obtenida del análisis espacial desde el programa ArcGIS y datos de campo. El área visible desde El Pacifico (en color verde), cubre casi toda la intercuenca y espacios colindantes de las cuencas del Chillón y el Rímac. 


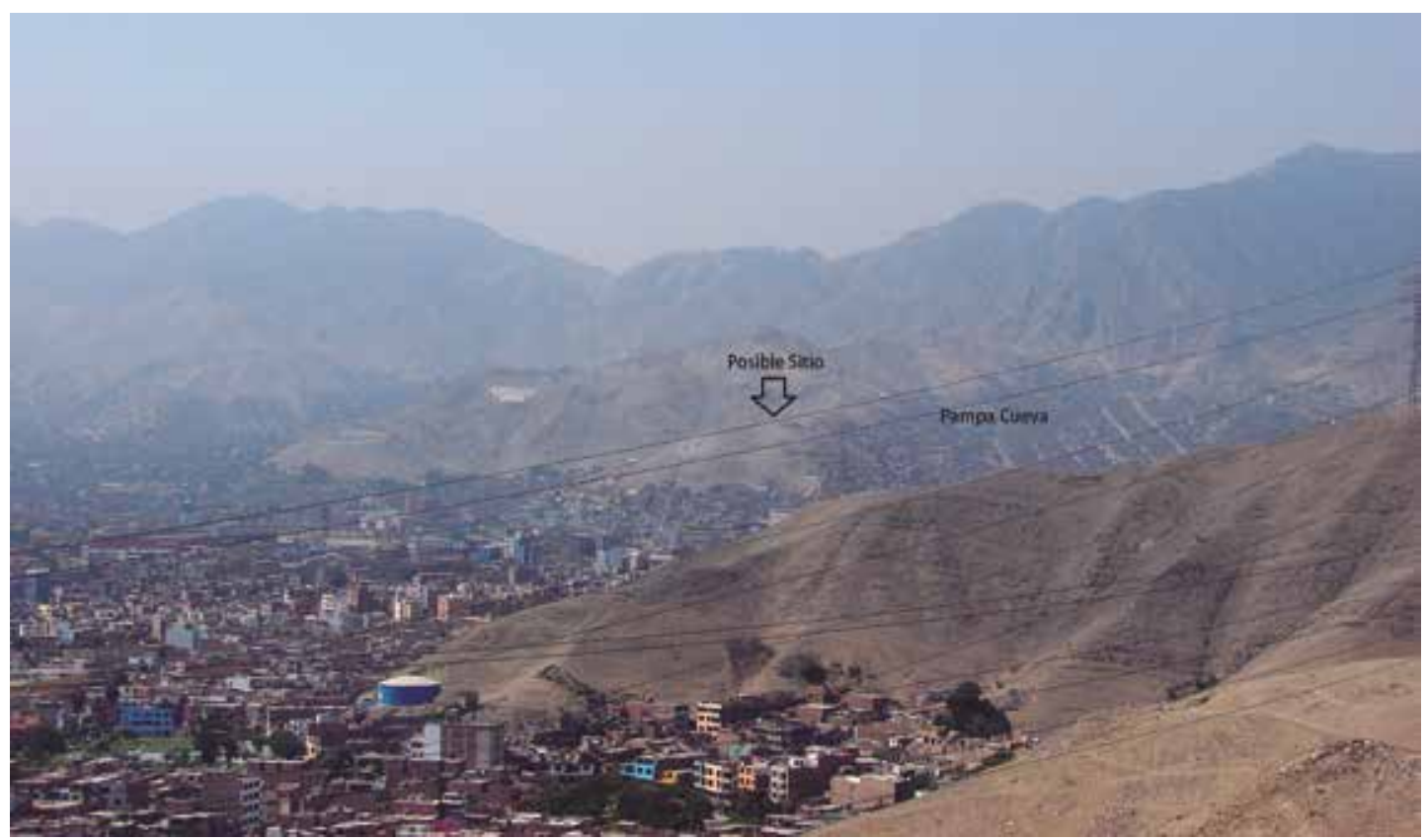

Fig. 9. Vista desde la cima del montículo del sector B de El Pacifico hacia Pampa Cueva (actual distrito de Independencia).

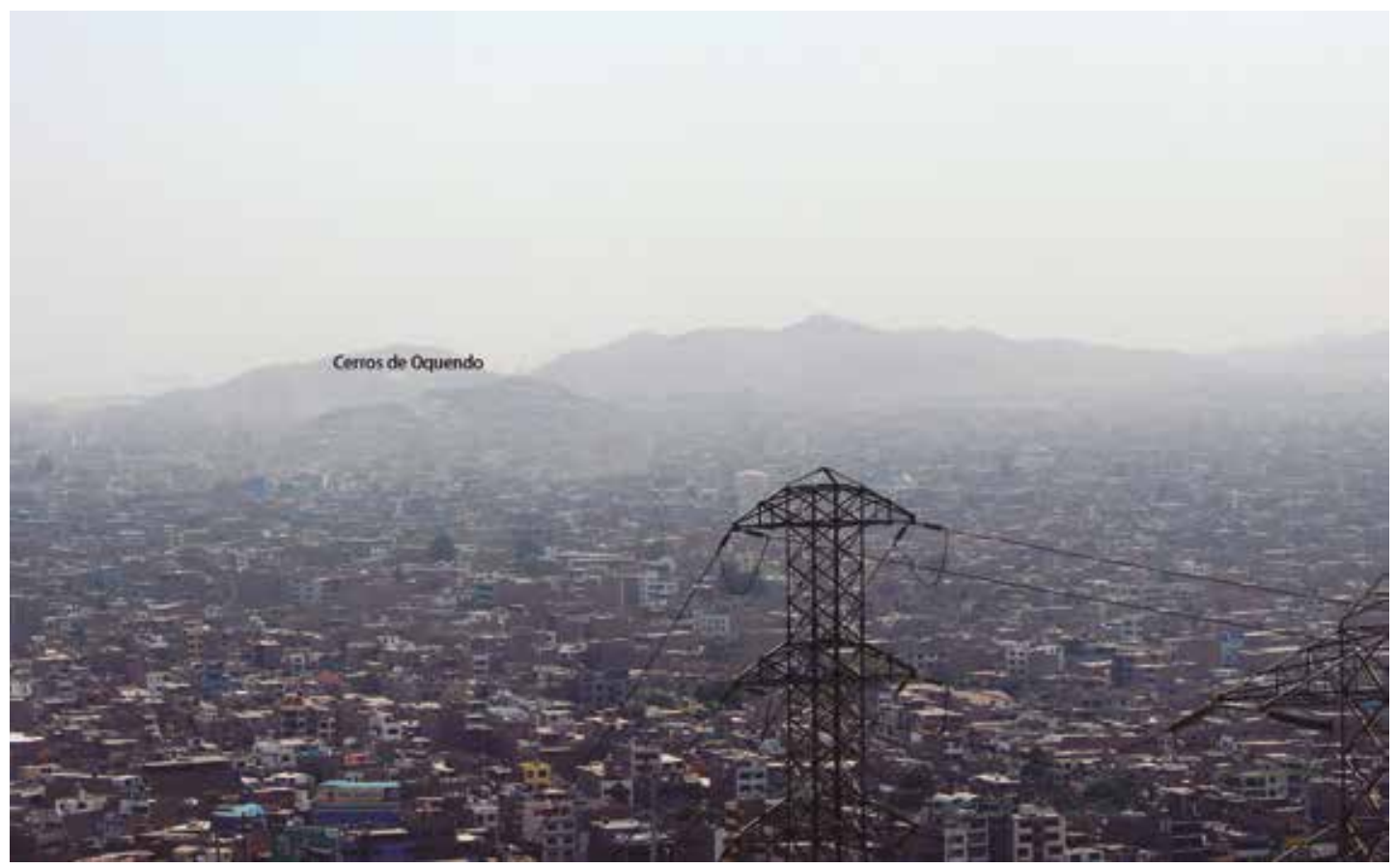

Fig. 10. Vista desde la cima del montículo del sector B de El Pacifico hacia los cerros de Oquendo (actual distrito de San Martin de Porras) 


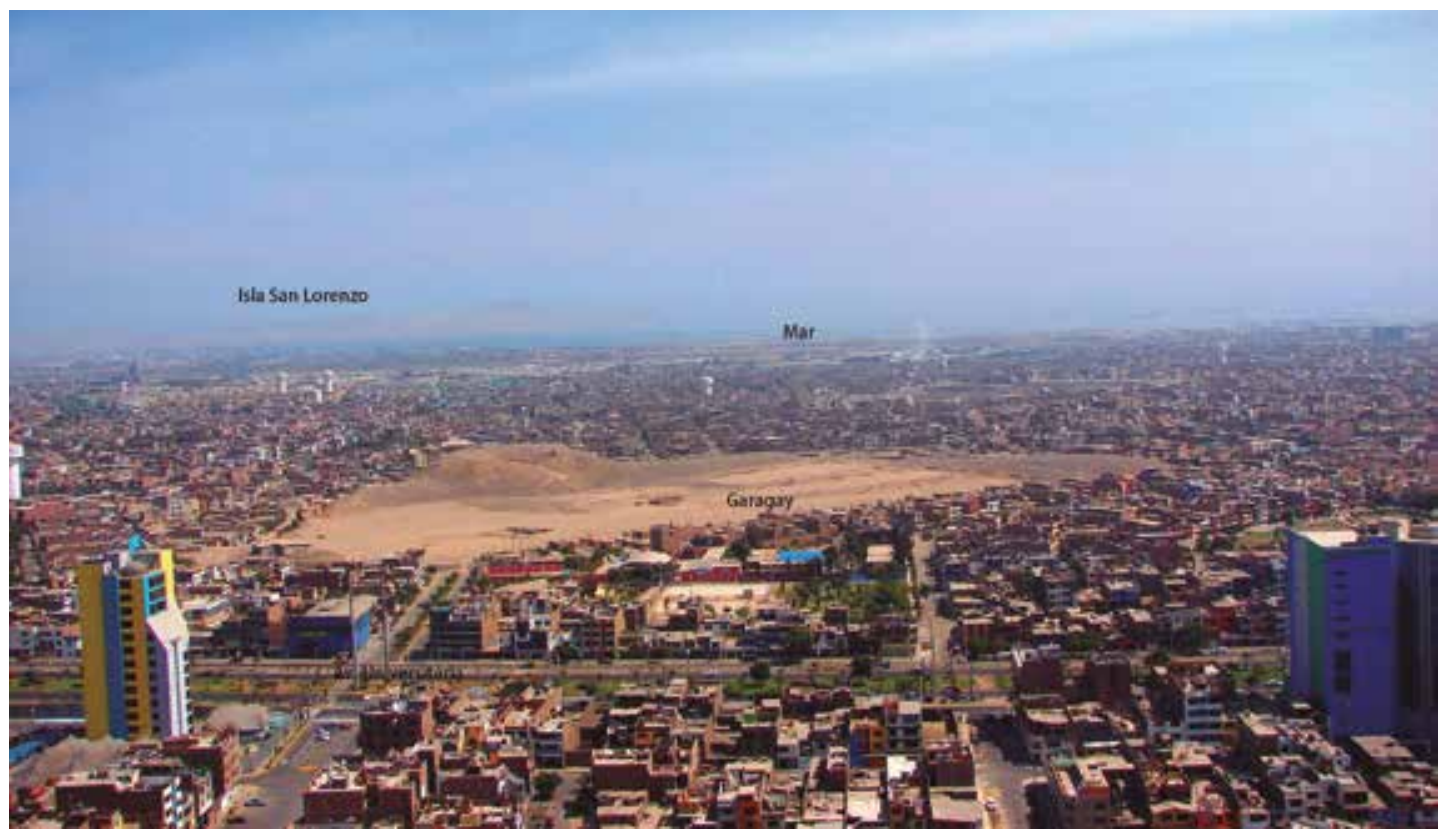

Fig. 11. Vista desde la cima del montículo del sector B de El Pacifico hacia el litoral costero (actual provincia del Callao).

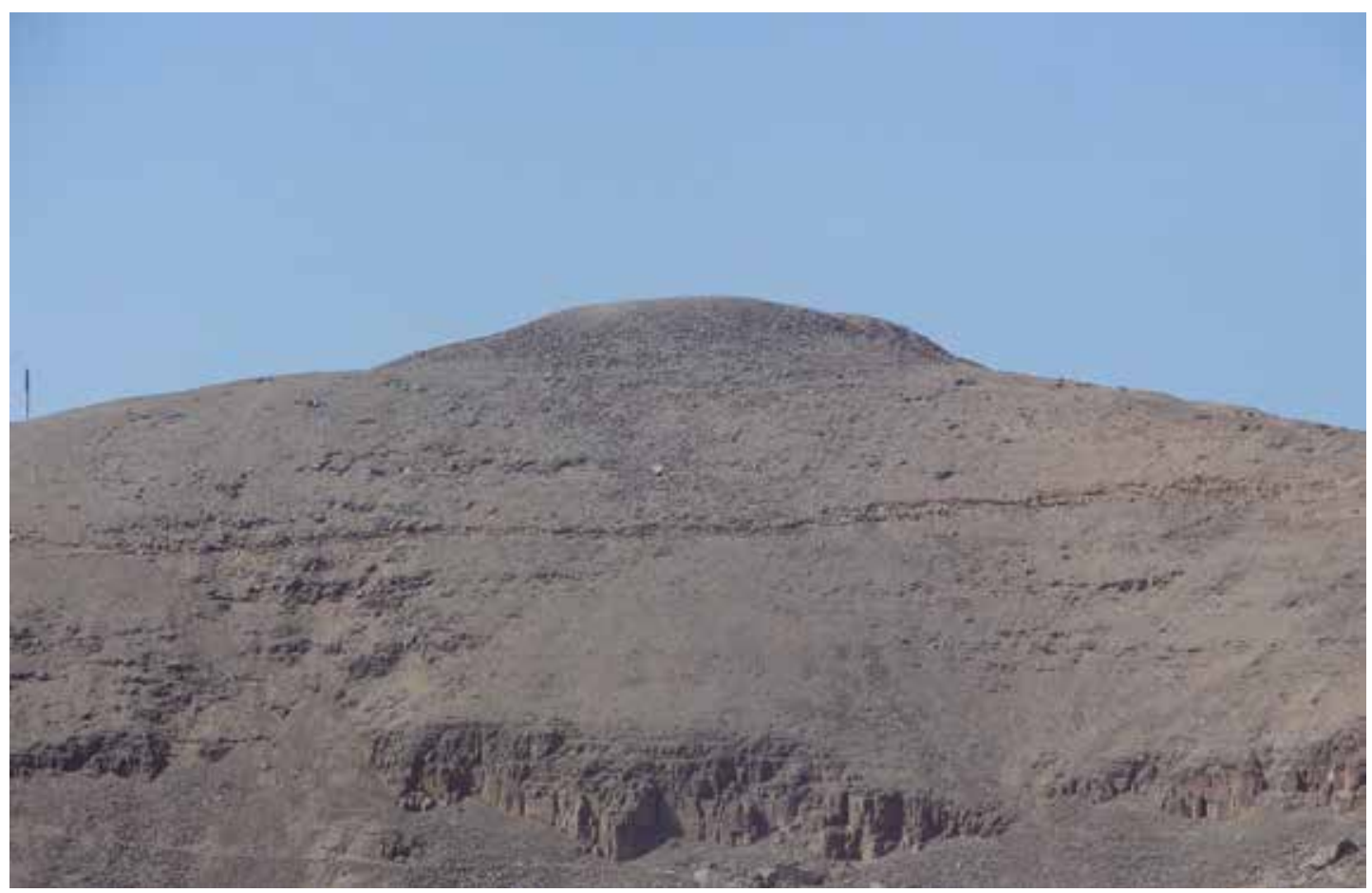

Fig. 12. Vista desde la avenida Universitaria del cerro el Pacifico, en cuya cima se observa el montículo del sector B. 
Formativo Medio como Garagay y Pampa de Cueva. Pero además se presumió que ello habría empezado tempranamente desde el periodo Arcaico Tardío y luego "se extendió hacia el Formativo" (Traslaviña et al. 2007: 43-44). Esta hipótesis es atractiva, pero de análisis sincrónico que asume varias condicionales. El primero de ellos es un supuesto cronológico, en la que los sitios del Formativo Temprano tuvieron componentes del precerámicos. No obstante no existe por ahora ninguna prueba para sustentar una ocupación tan temprana. Aunque no se puede descartar toda posibilidad por los casos ya examinados en el valle del Rimac. El segundo supuesto es la existencia de un sitio temprano sobre la cima del cerro próximo al costado de Pampa de Cueva deducido solo a partir de las formas concéntricas que puede apreciarse en una foto aérea (Traslaviña et al. 2007). Lamentablemente los pocos datos recogidos del sitio no corroboran tal afirmación ${ }^{2}$.

A pesar de nuestro cuestionamiento sobre la cronología, no se puede negar la gran visibilidad que existe desde/hacia El Pacifico. Precisamente para corroborar esto hemos realizado un examen digital y un ejercicio práctico de visibilidad. El estudio de patrones de visibilidad viene siendo ampliamente empleado como una forma de aproximarnos a la interpretación del paisaje como lugar social. La percepción visual ha sido usada en un intento por desanudar la asociación metafórica de ciertas configuraciones espaciales, como una de las formas de experimentar lo lugares, porque como lo han señalado algunos investigadores, ciertas materialidades -como los montículos- han sido construidos para ser notados, y ello puede proveernos una entrada para entender las intenciones pasadas (Criado-Boado 1995; Llobera 2007; Tilley 2010).

Para este examen usamos la herramienta de análisis espacial de superficie Viewshed total el programa ArcGIS. El punto de observación se dispuso digitalmente a $1.5 \mathrm{~m}$ (altura promedio-mínimo de una persona) y además se construyó líneas de visión (Construct Sigh Lines), igualmente usando ArcGIS. Todos estos análisis tomaron como referencia un punto de observación sobre la cima del cerro El Pacifico (Fig.8). Este resultado fue finalmente corregido con datos de campo. Como resultado se obtuvo una cuenca visual que incluyó por el este hasta las estribaciones costeras del actual distrito de Independencia, donde se ubica el cerro antes referido al costado del asentamiento Pampa de Cueva. Por el horizonte oeste abarcó hasta el mar. Mientras por el norte hay una amplia cuenca de visibilidad que incluso comprendió el sitio precerámico El Paraíso. El ejercicio práctico que hicimos luego fue corroborar esta visibilidad en el campo, desde el propio cerro El Pacifico. Efectivamente desde el sector B del sitio se pudo observar hacia el noreste muy fácilmente el cerro próximo a Pampa de Cueva (Fig.9), debido a que está muy cerca (3 km al noreste). Hacia el noroeste se apreciaron los cerros de Oquendo que circundan El Paraíso, aunque este último fue más complicado de detectar, toda vez que se ubica a casi $7 \mathrm{~km}$ hacia el noroeste y presentan una espesa neblina (Fig.10). Por el horizonte oeste se tiene un dominio visual de todo el piso del valle, donde sobresale el asentamiento Garagay, hasta la línea del mar a unos $6 \mathrm{~km}$, e incluso se aprecia la isla San Lorenzo (Fig.11). En último lugar, por el sureste se visualiza el cerro La Milla. Mediante un reconocimiento pedestre -como parte del Proyecto El Paraíso (Guillen 2013)- logramos detectar sobre las cimas de estos cerros una serie de habitáculos y plataformas menores, que debieron servir como observatorios. El propio Robert Benfer y sus colegas (2007) ya habían mencionado algunos de estos rasgos, que interpretaron como puntos asociados con alineaciones celestes.

2 El arqueólogo Daniel Chumpitaz ha realizado una excavación en dicho cerro y nos ha comentado el hallazgo de cerámica de la cultura Lima temprano (comunicación personal, junio 2016). Otro colega que ha visitado la zona es Pedro Espinoza quien dice haber observado un perfil de basural arqueológico con presencia de cerámica aparentemente del periodo Formativo (comunicación personal, mayo 2016). Más recientemente, el propio Abel Traslaviña (comunicación personal, abril 2016) visitó la zona y encontró algunas alineaciones de piedras. Actualmente sobre la cima del cerro existen antenas y un muro que lo cerca. 
Entonces, podemos concluir que una de las razones de la ubicación de El Pacifico sobre un cerro fue para tener una visibilidad casi completa de la intercuenca, pero al mismo tiempo para ser apreciado desde diferentes puntos del piso y cerros de los valles del Chillón y del Rímac. El Pacifico fue así, un hito de una franja visual mayor que configuró un paisaje social potente.

Así, los montículos en El Pacifico se unen al cerro, sirviéndose de la topografía natural para sobredimensionar la obra humana. El cerro sumado al montículo, por ejemplo del sector B, habría resultado en un paisaje que impresionó desde el horizonte. Hasta el día de hoy causa esa percepción, a pesar del crecimiento urbano (Fig.12). Esto seguramente en su intento por imponer un discurso social visualmente poderoso, que lo empoderó como un lugar significativo. Un lugar que habría permitido estabilizar e integrar a la comunidad.

\section{Problemas y Posibilidades de Investigar en el Pacífico}

En el propio ensayo de visibilidad que hemos realizado seguimos dependiendo de supuestos cronológicos. No contar con una cronología exacta para el sitio de El Pacifico lo sigue colocando en un limbo, Temporal. El tema cronológico hoy está más complejo, porque hasta hace un tiempo era casi un hecho que todo asentamiento sin evidencia de cerámica era asignable a un periodo anterior al 1800 a.C. Hoy la posibilidad de que algunos yacimientos sean acerámicos vuelve a la palestra. Ya desde hace varios años los esposos Pozorki (1990: 488-489; 1991; 1999: 179, tabla 2) han esgrimido que El Paraíso, Alto Salaverry y Las Salinas de Chao en realidad fueron sitios acerámicos al considerarlos contemporáneos con otros del Formativo Temprano. Más recientemente, el equipo de la Zona Arqueológica de Caral ha encontrado evidencias de una ocupación de un Formativo acerámico en Vichama, Huaura (Shady et al. 2014). En todo caso, los sitios acerámicos, con arquitectura pública, se abandonan o disminuyen considerablemente en cantidad, antes de la entrada de la cerámica, como sucede en la costa central. Y en los casos que persisten, se superpone a ellos una arquitectura distinta, en algunos casos más sencilla (Kaulicke 2010: 202). No obstante, este proceso fue desigual en los Andes, por ejemplo en el valle de Casma se da un auge portentoso, siendo los mejores ejemplos los asentamientos de las Haldas y Cerro Sechin (Kaulicke 2010). Entonces, más allá de los casos claros de la sierra (ej. Kotosh, Shillacoto, Wairajirca), en la costa también hay asentamientos con una superposición ocupacional potente; sin embargo, no hay pruebas que tuvieran una continuación directa (Kaulicke 2010). A pesar que la discusión está abierta desde hace décadas (Quilter 1991: 452) queda claro que se requiere hilar fino para reconstruir la historia de los periodos Formativo Inicial y Temprano de Lima, por ello es urgente obtener estratigrafías controladas y fechados desde contextos primarios. Lamentablemente son pocos los sitios del periodo formativo que han perdurado en los valles de Lima y mucho menos los que tienen ambos periodos superpuestos. Por ello, la investigación en El Pacifico es más que necesario, es una urgencia.

Precisamente en esta primera fase del proyecto hemos planteado hacer excavaciones restringidas (4 unidades de excavación que hacen un total de $40 \mathrm{~m} 2$ ). Y si bien no lograremos exponer amplias áreas, al menos nos permitirá tener un control vertical de la estratigrafía y determinar ciertos contextos, desde los cuales obtendremos muestras para fechados y con ello empezar a esclarecer el problema cronológico del yacimiento.

Por otro lado, investigar en un yacimiento temprano como El Pacifico tiene un gran potencial, porque va permitir plantear nuevas preguntas poco abordadas entre los estudiosos andinos. Como ya hemos señalado, los investigadores se han preocupado en responder acerca del origen del poder centralizado, y para ello han investigado en los asentamientos públicos mayores. Como consecuencia de ello no se conocen todos los tipos de sitios, y por tanto está incompleto el sistema de asentamientos. 
El Pacifico es un yacimiento menor, pero ubicado privilegiadamente sobre la cima de un cerro desde el cual, como ya hemos demostrado, se tuvo, y se tiene, una alta visibilidad.

Si bien somos conscientes de los límites de nuestro proyecto, pero más allá de proyectarnos solucionar problemas cronológicos y formales, intentaremos poner a prueba también interrogantes más sociales, en un intento por explorar otros caminos. Partimos de la idea que El Pacifico fue un espacio social para prácticas rituales, desde donde se comunicaron mensajes canónicos y de autoreferenciacion. Consideramos que el sitio representó un lugar monumental para las colectividades de los valles limeños, es decir un lugar desde donde se producía y reproducía la memoria de las comunidades, un palimpsesto histórico que sirvió para autoreferenciarse; pero al mismo tiempo, donde los grupos que llegaban a este lugar se les transmitía la visión del mundo (imago mundi), es decir las convenciones, preceptos morales e incluso las regulaciones de tiempo y espacio en las que debieran manejarse (Flores 2014; Rapoport 1969; Vega-Centeno 2006). Posiblemente estemos aquí ante un ejemplo antiquísimo, y poco conocido, de santuario costeño. Y tal vez esta sea otra razón -posiblemente la más importante- de la ubicación tan prominente de El Pacifico.

Las excavaciones irán revelando datos, pero al mismo tiempo será un buen escenario para dialogar, y porque no, confrontar y discrepar con cada uno de los planteamientos, problemas e ideas aun sueltas que he querido verter en este primero reporte. Los resultados que puedan obtenerse de esta conversación, entre el sitio y los arqueólogos, serán compartidos próximamente en un segundo reporte.

Agradecimientos: Este proyecto se ha convertido en una realidad gracias a una red de amigos y colegas. En primer lugar gracias al alcalde de Los Olivos, Pedro del Rosario, por confiar en esta propuesta, y dentro de dicha institución mi más sincero agradecimiento a Santiago Tácunan por ayudarme con la gestión. También gracias a Mark Aldenderfer y José Capriles por comprometerse con el presupuesto para los fechados. Gracias a Hector Walde por su ayuda logística. Agradezco también a Henry Arízaga por su gestión para el primer registro aéreo con dron realizado por la empresa REMOTE SENSING-COMTEC-Perú del señor Francisco Henríquez. En ese mismo sentido gracias a Erick Maquera y la empresa Arqueosystems SAC por el registro topográfico y cartográfico del asentamiento usando dron. La digitalización de la planimetría está a cargo de Luis Loza de ArqueoCAD. Agradecimientos para el colega Abel Traslaviña por compartir su conocimiento sobre el sitio. Pero este proyecto no sería posible sin la ayuda de una serie de colegas y estudiantes que soportaron los trabajos, especial mención merecen Norka Gamarra, Lucero Cayo, Katia Herrera, Katty Flores, Ángel Infantes, Alfredo Altamirano, Carmela Alarcón, Roxana Paucar, Jenifer Pérez, Luz Zelada, Joseph Chacón, Rosario Castillo, Diego Maravi, Miguel Castillo, Noelia Roa, Joseph Chacón, Diego Maravi, Pedro Salvador, Eduardo Chávez, Marco Valderrama, Rosa Carlos, Luis Miranda, Juan Pablo Villanueva, Humberto Chauca, Jesús Maza, María Quispe, quienes, entre otros, me ha asistido durante toda la investigación. Así como a cada uno de los más de treinta estudiantes de las universidades de San Marcos y Villarreal que participaron, como Raúl Huamán, Ruth Garay, Mauro Condori, André Valencia, Carlos Moreno, Tania Flores, Jessy Ponce, Daniela Guevara, Lucero Llancari, María Zamora, Rebeca Trujillo, Denys Silva, Eli Farfán, Carlos Chilón Ramírez, Alexander Obregón, Santiago Huertos, Sebastián Bernaola, Yerovi Marcelo, Lucero Cuellar, Lucia Ríos, Edson Palomino, Milton Ñahui, Sandra Paz, Julio Cisneros, Lorenzo Obregón, Andrés Salvatierra, Shym Yanfer, entre otros colegas y estudiantes que se han ido sumando al proyecto. 


\section{BiBLIOGRAFÍA}

ABANTO, Julio

2009 "Evidencias arqueológicas del periodo Formativo en la Quebrada de Canto Grande, valle bajo del Rímac". Boletín de Arqueología PUCP, 13: 159-185.

2013 "San Juan de Lurigancho y el origen de la civilización en los andes peruanos: Las primeras construcciones monumentales”. Lunes, 24 de junio de 2013. Fuente: http://www.sjl.pe/ noticias/noticia.asp?id=2665

AGUILAR, Miguel

2006 "Surgimiento de las sociedades complejas en los Andes Centrales. Una perspectiva desde el valle de Huaura, Perú". Monografía para optar el Título profesional de licenciatura, Universidad Nacional FedericoVillarreal.

BENFER JR., Robert; Bernardino OJEDA; Neil A. DUNCAN; Larry R. ADKINS; Hugo LUDEÑA; Miriam VALLEJOS; Víctor ROJAS; Andrés OCAS; Omar VENTOCILLA; y Gloria VILLAREAL

2007 “La Tradición Religioso-Astronómica en Buena Vista”. Boletín de Arqueología PUCP (Procesos y Expresiones de Poder, Identidad y Orden Tempranos en Sudamérica. Segunda Parte), $\mathrm{N}^{\circ}$ 11, pp. 53-102. Pontificia Universidad Católica del Perú. Lima.

BONNIER, Elizabeth

1997 "Preceramic Architecture in the Andes: the Mito Tradition”. En Archaeological Peruana 2, editado por Bonnier y H. Bischof, pp. 121-144. SAPA. Reiss-Musseum Mannheim.

BUENO, Alberto

1997 “El Formativo: Análisis, Revisión y Propuestas”. En Revista del Museo de Arqueología, Antropología e Historia, 7: 65-86.

CAYO QUISPE, Lucero

2015 “La tradición arquitectónica Paraíso del valle bajo del rio Rímac". Informe de Practicas Pre-Profesionales de Arqueología, UNMSM.

CHU, Alejandro

2006 “Arquitectura monumental precerámica de Bandurria, Huacho”. Boletín de Arqueología PUCP, 10: 91-109.

2008 Bandurria. Arena, mar y humedal en el surgimiento de la Civilización Andina. Proyecto Arqueológico Bandurria - Huacho.

CORNEJO, Cesar

2012 Pampa de los Perros y el Precerámico Final en la Costa Central del Perú. Tesis para optar el Título Profesional de Licenciado en Arqueología. Escuela Académico Profesional de Arqueología, Facultad de Ciencias Sociales, Universidad Nacional Mayor de San Marcos. Lima.

2013 “Arquitectura precerámica monumental en la costa central: la tradición El Paraiso”. Revista Investigaciones Sociales, 17 (30): 105-129, UNMSM-IIHS. LIMA, PERÚ. 
CREAMER, Winifred; Álvaro RUIZ; Manuel F. Perales, Jonathan Haas

2013 “The Fortaleza Valley, Peru: Archaeological Investigation of Late Archaic Sites (3000-1800 BC)”. Fieldiana Anthropology, № 44:1-108.

CRIADO-BOADO, Felipe

1995 "The visibility of the archaeological record and the interpretation of social reality". In Interpreting Archaeology: Finding Meaning in the Past (eds I. Hodder, M. Shanks, A. Alexandri, V. Buchli, J. Carman, J. Last and G. Lucas). London: Routledge.

DILLEHAY, T.D.; D. BONAVIA; S. GOODBRED; M. PINO; V. VASQUEZ; T. ROSALES; W. CONKLIN, J. SPLITSTOSER; D. PIPERNO; J. IRIARTE; A. GROBMAN; G. LEVI-LAZZARIS; D. MOREIRA; M. LOPEZ; T. TUNG; A. TITELBAUM; J. VERANO; J. ADOVASIO; L. SCOTT; P. BEAREZ; E. DUFOUR; O. TOMBRET; M. RAMIREZ; R. BEAVINS; L. DESANTIS; I. REY; P. MINK; G. MAGGARD; y T. FRANCO

2012 "Chronology, mound-building and environment at Huaca Prieta, coastal Peru, from 13700 to 4000 years ago". Antiquity, 86: 48-70.

\section{EL COMERCIO}

2011 “Lima milenaria: huaca en Huachipa es tan antigua como Caral”. Publicación del sábado 03 de diciembre del 2011 | 09:02 (leída el 04 de mayo del 2016): http://elcomercio.pe/lima/ sucesos/huaca-huachipa-tan-antigua-como-caral-noticia-1342928

ENGEL, Frédéric

1957 “Early sites on the Peruvian coast”. Southwestern Journal of Anthropology 13: 54-68.

1958 “Algunos datos con referencia a los sitios precerámicos de la costa peruana”. En Arqueológicas 3. Publicación del Instituto de Investigaciones Antropológicas de la MNAA, Lima.

1966a “El Conjunto Pre Cerámico de Chuquitanta”. El Arquitecto Peruano, marzo-abril, no. 338-339, pp. 53-55. Lima.

1966b “Le Complexe Précéramique d'el Paraiso (Pérou)". Journal de la Société des Américanistes, tomo LV-I, pp. 43-95. Musée de L'Homme. París.

1967 “El Complejo El Paraíso en el Valle del Chillón, Habitado hace 3500 Años; Nuevos Aspectos de la Civilización de los Agricultores del Pallar". Anales Científicos, vol. V, julio-diciembre, no. 3-4, pp. 241-280. Departamento de Publicaciones de la Universidad Nacional Agraria La Molina. Lima.

1987 De las Begonias al Maíz. Vida y Producción en el Perú Antiguo. Centro de Investigaciones de Zonas Áridas (CIZA), Universidad Nacional Agraria La Molina. Lima.

ESCARCENA, Pablo

2010 Investigaciones arqueológicas en Chira-Villa. Tesis para optar el título de licenciado en Arqueología, Universidad Nacional Mayor de San Marcos.

FELDMAN, Robert

1980 Aspero, Peru: Architecture, Subsistence Economy and Other Artifacts of a Preceramic Maritime Chiefdom. Thesis presented for the degree of Philosophy. Harvard University, Cambridge, Massachusetts; 290 pp. 
FLORES BLANCO, Luis

2006 Estudio de Unidades Residenciales en el Subsector I2 de Caral, valle de Supe - Perú. Tesis para obtener el Título de Licenciatura. UNMSM.

2014 "El surgimiento del paisaje monumentalizado en la cuenca del lago Titicaca, Andes Centro-Sur". Complutum [Madrid], 25 (1): 47-71.

FUCHS, P.; R. PATZSCHKE; G. YENQUE; Jesús BRICEÑO

2009 "Del Arcaico Tardío al Formativo Temprano: las investigaciones en Sechín bajo, valle de Casma". Boletin de Arqueologia PUCP, 13: 55-86.

FUENTES SADOWSKI, José

2009 La Secuencia Cronológica de la Huaca La Florida, valle del Rímac, Perú. Tesis para obtener el Título de Licenciatura. UNMSM.

GUILLÉN, Marco

2013 Informe Final del PIA Puesta en Valor de la Zona Arqueológica Monumental El Paraíso. Reporte entregado al Ministerio de Cultura, Perú. Ms.

HAAS, Jonathan

1987 “The Exercise of Power in Early Andean State Development”. The Origins and Development of the Andean State. J. Haas, S. Pozorski y T. Pozorski (eds.), pp. 31-55. Cambridge University Press, NY.

HAAS, Jonathan y Winifred CREAMER

2006 "Crucible of Andean Civilization. The Peruvian Coast from 3000 to 1800 BC". Current Anthropology 47 (5): 745-775.

HAAS, Jonathan; Winifred CREAMER y Alvaro RUIZ

2004 "Dating the Late Archaic occupation of the Norte Chico Region in Peru". Nature, 432: 10201023.

KAULICKE, Peter

2010 Las Cronologías del Formativo. 50 años de investigaciones japonesas en perspectiva. Fondo editorial de la PUCP, Lima.

KAULICKE, Peter y Tom DILLEHAY

1999 “Introducción: ¿Por qué estudiar el Periodo Arcaico en el Perú?” Boletín de Arqueología PUCP 3: 9-17.

LANNING, Edward

1960 Chronological and Cultural Relationships of Early Pottery Styles in Ancient Peru. Ph.D. dissertation, University of California. Berkeley, California.

1967 Peru before the Incas. Prentice-Hall, Inc. New Jersey.

LUDEÑA, Hugo

1973 Investigaciones arqueológicas en el sitio de Huacoy, valle del Chillón. Tesis de Bachillerato inédita, Universidad Nacional Mayor de San Marcos, Lima. 
LUJAN, Milton

2011 Informe final del Proyecto de Evaluación Arqueológica en los terrenos de la Empresa Olivos 3088 SAC en los cerros Mulería y Pacifico, distrito de los Olivos, provincia Lima.

LUMBRERAS, Luis

2006 “Un Formativo sin cerámica y cerámica preformativa”. Estudios Atacameños, 32: 11-34.

LLOBERA, Marcos

2007 “Reconstructing visual landscapes". World Archaeology 39 (1): 51-69.

MOSELEY, Michael

1975 The Maritime Foundations of Andean Civilization. Cummings Publishing Company. Menlo Park, California.

ONUKI, Yoshio

1999 “El Periodo Arcaico en Huanuco y el Concepto del Arcaico". En: Boletín de Arqueología PUCP, 3: 325-333.

PATTERSON, Thomas; y Edward LANNING

1964 “Changing Settlement Patterns on the Central Peruvian Coast”. En: Ñawpa Pacha, N², pp. 113-123. Instituto de Estudios Andinos. Berkeley.

PATTERSON, Thomas y Michael MOSELEY

1968 "Late Preceramic and Early Ceramic Cultures of the Central Coast of Peru”. En: Ñawpa Pacha, $\mathrm{N}^{\circ}$ 6: 115-133. Instituto de Estudios Andinos. Berkeley.

PERALES, Manuel

2006 "Informe Final del Proyecto de Investigación: Reconocimiento Arqueológico en el Valle Bajo de Pativilca, Lima - Perú". Reporte presentado al INC.

POZORSKI, Shelia; y Thomas POZORSKI

1990 "Reexamining the Critical Preceramic/Ceramic Period Transition: New Data from Coastal Peru". American Anthropologist, vol. 92, № 2, pp. 481-491. Menasha.

1991 “The Impact of Radiocarbon Dates on the Maritime Hypothesis: Response to Quilter". American Anthropologist, vol. 93, № 2, pp. 454-455. Menasha.

POZORSKI, Thomas; y Shelia POZORSKI

1999 “Una Reevaluación del Desarrollo de la Sociedad Compleja durante el Precerámico Tardío en Base a los Fechados Radiocarbónicos y a las Investigaciones Arqueológicas en el Valle de Casma". Boletín de Arqueología PUCP (El Periodo Arcaico en el Perú: Hacia una Definición de los Orígenes), № 3, pp. 171-186. Departamento de Humanidades, Pontificia Universidad Católica del Perú. Lima.

QUILTER, Jeffrey

1985 “Architecture and Chronology at El Paraíso, Peru”. Journal of Field Archaeology, 12 (3): 279297. Boston.

1991 "Problems with the Late Preceramic of Peru". American Anthropologist, 93 (2): 450-454. Menasha. 
QUILTER, Jeffrey; Bernardino OJEDA E.; Deborah M. PEARSALL; Daniel H. SANDWEISS; John G. JONES; y Elizabeth S. WING

1991 “Subsistence Economy of El Paraíso, an Early Peruvian Site”. Science, 251 (4991): 277-283. Washington D.C.

RAPOPORT, Amos

1969 House form and Culture. Milwaukee, University of Wisconsin.

RAVINES, Roger

1991 “Garagay: Un centro ceremonial del periodo Formativo”. Los Incas y el Antiguo Perú, 3000 años de Historia. Centro Cultural de la Villa de Madrid, España.

RAVINES, Rogger y William H. ISBELL

1975 “Garagay, Sitio Ceremonial Temprano en el valle de Lima”. Revista del Museo Nacional 41: 253-275.

ROSELLÓ, Lorenzo

1997 Cantogrande y su relación con los Centros Ceremoniales de Planta en 'U'. Lima, Mundo Gráfico S.A. SILVA, Jorge

1996 Prehistoric Settlement Patterns in the Chillón River Valley, Peru. Ph.D. dissertation. Department of Anthropology, University of Michigan. Ann Arbor, Michigan.

SILVA, Jorge y Cecilia JAIME

2000 "Investigación y delimitación de huacoy, carabayllo: notas preliminares". Investigación sociales IV(6): 55-70.

SHADY, Ruth

1997 La ciudad sagrada de Caral-Supe en los albores de la civilización en el Perú. Lima: Universidad Nacional Mayor de San Marcos.

2003 Caral-Supe. La Civilización más antigua de América. PEACS/INC.

2004 Caral. La Ciudad del Fuego Sagrado. Lima: Centura SAP, Banco Interbank, IFH Perú Ltd.

2005 “Caral-Supe y su entorno natural y social en los orígenes de la civilización”. Investigaciones Sociales [Lima], 9 (14): 89-120.

2006a "La civilización Caral: sistema social y manejo del territorio y sus recursos. Su trascendencia en el proceso cultural andino”. Boletín de Arqueología PUCP, 10: 59-89.

$2006 b$ “America's First City? The Case of Late Archaic Caral”. En: W. Isbell y H. Silverman (editores), Andean Archaeology III. North and South. Capítulo 2: 28-66.

SHADY, Ruth; Jonathan HAAS y Winifred CREAMER

2001 "Dating Caral, a Preceramic Site in the Supe Valley on the Central Coast of Peru". En: Science, 292: 723-726.

SHADY, Ruth y Daniel CÁCEDA

2006 Áspero. La Ciudad Pesquera de los Orígenes de la Civilización. Zona Arqueológica Caral. Lima. 
SHADY, R.; C. DOLORIER, F. MONTESINOS y L. CASAS

2000 "Los orígenes de la civilización en el Perú: el área norcentral y el valle de Supe durante el Arcaico Tardío”. Arqueología y Sociedad [Lima], 13: 13-48.

Shady, Ruth y Carlos LEYVA (eds)

2003 La Ciudad Sagrada de Caral-Supe. Lima: Proyecto Especial Arqueológico Caral Supe (PEACS)Instituto Nacional de Cultura (INC).

SHADY, R.; M. MACHACUAY; P. NOVOA; E. QUISPE; C. LEYVA

2016 Centros Urbanos de la Civilización Caral: 21 años recuperando la historia sobre el Sistema Social. Zona arqueológica Caral.

SHADY, Ruth; Pedro NOVOA y Marco MACHACUAY

2014 VICHAMA. Civilización agropesquera de Vegueta - Huaura: La ideología de nuestros ancestros, 3800 años de arte mural. ZAC / MC.

SHIBATA, Koichiro

2004 "Nueva cronología tentativa del período Formativo: Aproximación a la arquitectura ceremonial." Desarrollo Arqueológico. Costa Norte del Perú, editado por Luis Valle Álvarez, vol. I, pp. 79-98. Trujillo: Ediciones SIAN.

TILLEY, Christopher

2010 Interpreting Landscapes: Geologies, Topographies, Identities; Explorations in Landscape Phenomenology 3. Left Coast Press.

TOSSO, Walter; Luis FLORES; Marco Valderrama

2016 "Las Shicras en la Emergencia de la Complejidad Arcaica”. Revista Histórica, tomo XLVII: 321- 340.

TRASLAVIÑA, Teddy; Natalia HARO; Edgar BAUTISTA

2007 “El Pacifico: Evidencias de un probable sitio del Arcaico Tardío en el valle del Rímac”. Revista de Ciencias Sociales, I (1): 31-54.

VEGA-CENTENO, Rafael

2010 "Cerro Lampay: Architectural Design and Human Interaction in the North Central Coast of Peru”. Latin American Antiquity, 21 (2): 115-145.

2006 “El estudio arqueológico del ritual". Investigaciones Sociales, X (16): 171-192.

2005 "Ritual and Architecture in a Context of Emergent Complexity: A Perspective From Cerro Lampay, a Late Archaic site in the Central Andes". Dissertation Submitted to the Facultaty of the Department of Anthropology for the degree of Doctor of Philosophy in The University of Arizona.

VEGA-CENTENO, R., L. VILLACORTA, L. CACERES, G. MARCONE

1998 “Arquitectura Monumental Temprana en el Valle Medio de Fortaleza”. Boletín de Arqueología PUCP, 2: 219-238. Lima.

UHLE, Max

1910 "Las Civilizaciones Primitivas en los Alrededores de Lima". Revista Universitaria. Órgano de la UNMSM, V (I): 333-347, Lima. 